\title{
LA-UR-12-25437
}

Approved for public release; distribution is unlimited.

Title:

Author(s):

Intended for:

\section{Zone Refining for Low Loss Plutonium Purification}

Freibert, Franz J.

Report

\section{- Losalamos

\author{
EST. 1943
}

Disclaimer:

Los Alamos National Laboratory, an affirmative action/equal opportunity employer,is operated by the Los Alamos National

Security, LLC for the National NuclearSecurity Administration of the U.S. Department of Energy under contract DE-AC52-06NA25396.

By approving this article, the publisher recognizes that the U.S. Government retains nonexclusive, royalty-free license to

publish or reproduce the published form of this contribution, or to allow others to do so, for U.S. Government purposes.

Los Alamos National Laboratory requests that the publisher identify this article as work performed under the auspices of the

U.S. Departmentof Energy. Los Alamos National Laboratory strongly supports academic freedom and a researcher's right to publish; as an institution, however, the Laboratory does not endorse the viewpoint of a publication or guarantee its technical correctness. 


\title{
Zone Refining for Low Loss Plutonium Purification
}

Franz Freibert, MST-16

\begin{abstract}
In an effort to enhance plutonium purification capabilities at Los Alamos National Laboratory, further develop of the currently existing zone refining capabilities is needed to create a functional low loss processing option in support of programmatic and materials science research activities. Currently, the most effective process for converting impure plutonium dioxide ( 96\% pure) to high-purity plutonium metal $(>99.9 \%)$, consists of the following steps: (1) reducing the dioxide to an impure Plutonium metal with calcium metal in molten calcium chloride, (2) casting the impure metal into an anode and (3) electrorefining the impure metal to produce high-purity plutonium metal. The final step in this method is only $83 \%$ efficient as compared to the $>95 \%$ efficiency of the other processing steps. Other more efficient processing methods are desirable to enhance current purification activities, thereby, reducing waste generation and conserving precious materials in need of purification. Although zone refining has been used extensively to purify many lanthanides and actinides, its usefulness in purifying plutonium has yet to be fully realized. .
\end{abstract}

\section{Current Method of Plutonium Purification}

Purification of plutonium dioxide $\left(\mathrm{Pu}_{2}\right)$ currently takes place through a series of processing steps, which include direct dioxide reduction (DOR), metal casting and electrorefining (ER). Since 1979, the combination of DOR and ER has been employed for the routine re-cycling of impure $\mathrm{PuO}_{2}$ to high purity metal. This process for converting impure plutonium dioxide ( $96 \%$ pure) to high-purity plutonium metal (>99.9\%), consists of the following steps: (1) reducing the dioxide to an impure plutonium metal with calcium metal in molten calcium chloride, (2) casting the impure metal into an anode, and (3) ER the impure metal to produce high-purity plutonium metal. A flow diagram describing the processing steps of current technology used in processing $\mathrm{PuO}_{2}$ to obtain purified $\mathrm{Pu}$ metal can be seen in Figure 1. Operational limits on DOR and ER chemical purification specifications for feed can be seen in Table 1.

\section{Direct Oxide Reduction of $\mathrm{PuO}_{2}$}

The use of DOR procedures for the routine processing of plutonium dioxide to metal was developed in 1975-1976. A review of this processing step for reducing plutonium compounds to metal is given in Ref. 1 and Ref. 3. Briefly, the reduction of $\mathrm{PuO}_{2}$ by Ca metal is done in a $\mathrm{CaC1}_{2}$ solvent. The reaction goes according to the following reaction:

$$
\mathrm{PuO}_{2}(\mathrm{~s})+2 \mathrm{Ca}(\mathrm{l})+11 \mathrm{CaCl}_{2}(\mathrm{l}) \rightarrow 2 \mathrm{CaO} \bullet 11 \mathrm{CaC1}_{2}(\mathrm{l})+\mathrm{Pu}(\mathrm{l})
$$

Thus, the $\mathrm{CaC}_{2}$ dissolves the $\mathrm{CaO}$ by-product permitting coalescence of plutonium metal in a pool. 
The success of DOR is dependent on many parameters. The four most important are:

- Effective stirring of the reaction mixture is absolutely essential because poor stirring will result in incomplete reduction of $\mathrm{PuO}_{2}$, poor metal collection, and poor metal-salt phase separation.

- Solvent limits, based on solubility, for which a value of $0.17 \mathrm{~g} \mathrm{Pu} / \mathrm{g} \mathrm{CaC} 1_{2}$ has been established for practical operating conditions. Light element oxides impurity processing result in $\mathrm{CaO}$ production, which can interfere with the $\mathrm{PuO}_{2}$ reduction, thus resulting in poor plutonium metal collection.

- Bath temperature measurement is essential in the DOR process. Stirrer initiation and stirring rates are controlled by temperature measurement. Control of the melt temperature is important in achieving maximum solubility of $\mathrm{CaO}$ in $\mathrm{CaCl}_{2}$ and in minimizing the attack of the $\mathrm{MgO}$ crucible by liquid calcium.

- Anhydrous constituents $\left(\mathrm{CaCl}_{2}\right.$ and $\left.\mathrm{PuO}_{2}\right)$ are critical; otherwise, foaming during heat up and melting occurs, which results in a poor reduction yield.

\section{Casting Pu Metal}

After the reduction of the impure metal, the metal must be cast into a shape that is compatible with the ER cell. This requires alloying and casting the metal into a cylindrical ingot shape. The shape of the ingot is a 7.3-cm-diam cylinder, which is up to $10 \mathrm{~cm}$ long. The quantity of metal needed for ER is 6 kg. Because of nuclear criticality concerns, $6 \mathrm{~kg}$ of $\alpha$-phase (or near full density) metal is not allowed in the cylindrical configuration. As a result of these criticality constraints, the metal is alloyed with gallium during the casting phase in order to change the bulk density from $>19 \mathrm{~g} / \mathrm{cm}^{3}$ down to $<16.5 \mathrm{~g} / \mathrm{cm}^{3}$. The ingot-casting step involves heating the metal buttons under a vacuum to above the metal melting point. The metal is mixed with the gallium and then bottom-poured from the crucible into the mold. A casting residue, or skull, always occurs. This skull contains many light-element impurities, dioxide films, or high-melting contaminants that exist in the impure-metal buttons. The casting yield is typically $95 \%$. 


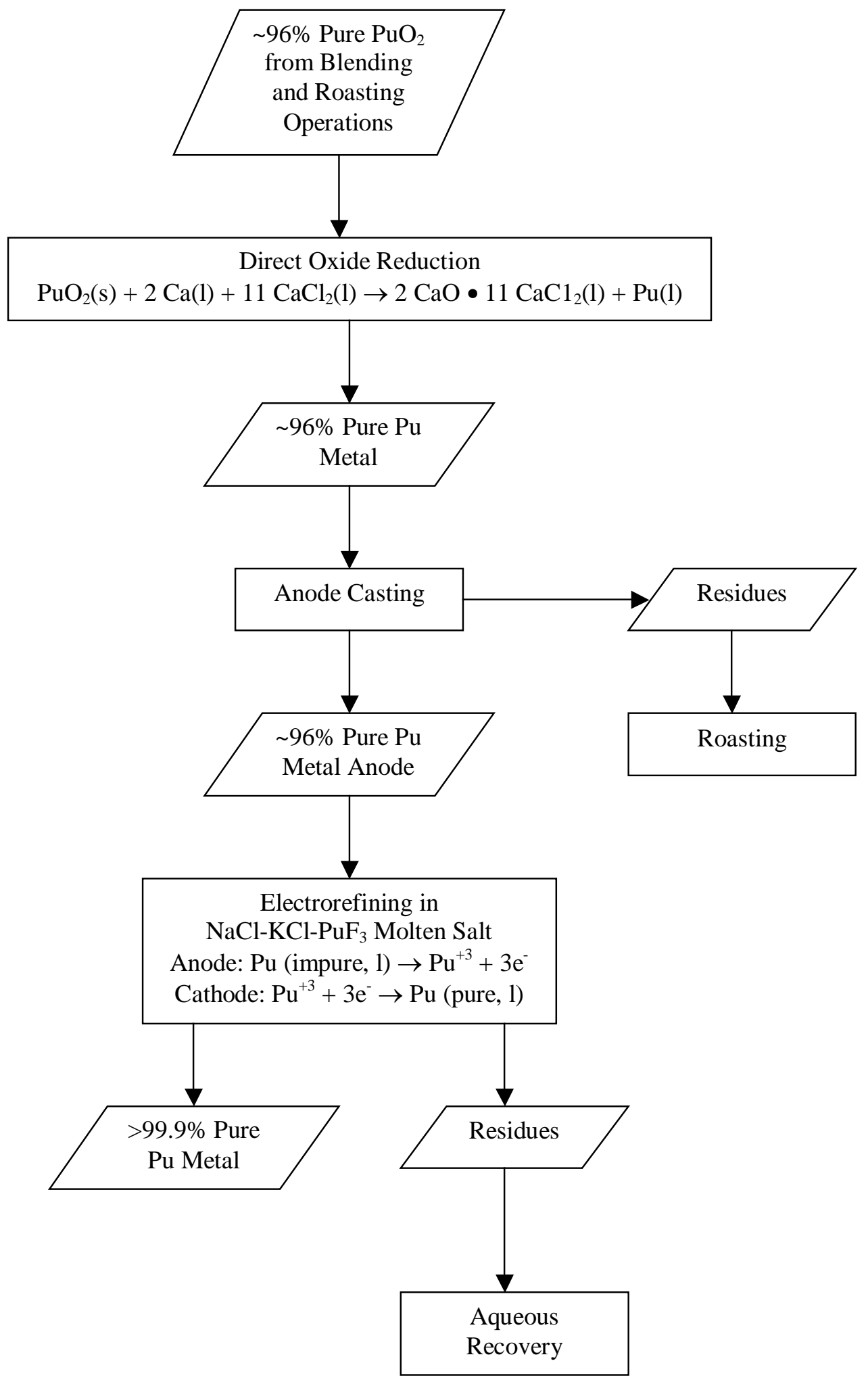

Figure 1 Flow Diagram of the processing steps in current $\mathrm{PuO}_{2}$-to-Pu metal purification operations. 


\section{Electrorefining $\mathrm{Pu}$}

The use of ER for the routine processing of impure plutonium metals and alloys to high-purity metal has been an established procedure at Los Alamos since 1964. Plutonium ER principles are summarized in Ref .2 and Ref. 3. Briefly, the processing step consists of oxidizing plutonium from an impure metal feed at the anode and reducing it to pure metal at the cathode, that is,

$$
\begin{array}{lc}
\text { Anode: } & \mathrm{Pu} \text { (impure, } \mathrm{l}) \rightarrow \mathrm{Pu}^{+3}+3 \mathrm{e}^{-} \\
\text {Cathode: } & \mathrm{Pu}^{+3}+3 \mathrm{e}^{-} \rightarrow \mathrm{Pu} \text { (pure, l) } \\
\text { Net Reaction: } & \mathrm{Pu} \text { (impure, } \mathrm{l}) \rightarrow \mathrm{Pu} \text { (pure, } \mathrm{l} \text { ). }
\end{array}
$$

The process is done at $740^{\circ} \mathrm{C}$ in a molten salt consisting of $\mathrm{NaC1}-\mathrm{KCl}-\mathrm{PuF}_{3}$, under near-equilibrium conditions. Virtually all of the impurities concentrate in the anode. Of the impurities usually present in plutonium, only americium concentrates in the salt.

Product yields are a function of anode depletion and metal collection and are typically $82.5 \%$ effective. The plutonium product, which is not collected as yield, exists in several forms: (1) the metal remains as unconsolidated plutonium shot, (2) some metal reacts with the crucible wall to which it adheres, and (3) a smaller amount is unreduced $\mathrm{Pu}^{+3}$. As shown in Table 1, the ER process possesses tremendous purification capabilities. Product purity is essentially insensitive to the purity of the feed metal. The only real requirement for the feed is that it be molten or contain a single liquid and solid phase at the temperature of the ER reaction.

Table 1 Operational limits on DOR and ER chemical purification specifications for dioxide feed. ${ }^{3}$

\begin{tabular}{cccc}
\hline Element & $\begin{array}{c}\text { Maximum Limits for DOR } \\
\text { Feed (Wt. \%) }\end{array}$ & $\begin{array}{c}\text { DOR Product - Electrorefining } \\
\text { Feed (Wt. PPM) }\end{array}$ & $\begin{array}{c}\text { Electrorefining Product } \\
\text { (Wt. PPM) }\end{array}$ \\
\hline \hline Li & No Limit & $<1$ & $<0.005$ \\
$\mathrm{Be}$ & 0.01 Max & 250 & 10 \\
$\mathrm{~B}$ & No Limit & $<10$ & $<0.05$ \\
$\mathrm{Na}$ & 0.25 & 110 & $<10$ \\
$\mathrm{Mg}$ & 0.25 & 300 & 1 \\
$\mathrm{Al}$ & 0.20 & 2000 & $<1$ \\
$\mathrm{Si}$ & 0.10 & 320 & $<5$ \\
$\mathrm{~K}$ & No Limit & 45 & $<10$ \\
$\mathrm{Ca}$ & No Limit & 500 & $<10$ \\
$\mathrm{Sc}$ & 0.10 & - & -
\end{tabular}




\begin{tabular}{|c|c|c|c|}
\hline Element & $\begin{array}{c}\text { Maximum Limits for DOR } \\
\text { Feed (Wt. \%) }\end{array}$ & $\begin{array}{l}\text { DOR Product - Electrorefining } \\
\text { Feed (Wt. PPM) }\end{array}$ & $\begin{array}{l}\text { Electrorefining Product } \\
\text { (Wt. PPM) }\end{array}$ \\
\hline $\mathrm{Ti}$ & 1.5 & 15000 & 10 \\
\hline $\mathrm{V}$ & 0.10 & - & - \\
\hline $\mathrm{Cr}$ & No Limit & 340 & $<5$ \\
\hline $\mathrm{Mn}$ & 0.10 & 200 & $<0.1$ \\
\hline $\mathrm{Fe}$ & 2.5 & 25800 & 20 \\
\hline Co & 2.3 & 23000 & $<0.5$ \\
\hline $\mathrm{Ni}$ & 0.50 & $>1000$ & $<0.5$ \\
\hline $\mathrm{Cu}$ & 0.50 & 500 & $<1$ \\
\hline $\mathrm{Zn}$ & 0.50 & 1000 & $<5$ \\
\hline $\mathrm{Ga}$ & 1.0 & 12900 & $<20$ \\
\hline $\mathrm{Rb}$ & No Limit & - & - \\
\hline $\mathrm{Sr}$ & No Limit & - & - \\
\hline $\mathrm{Y}$ & 0.80 & 8000 & $<0.4$ \\
\hline $\mathrm{Zr}$ & 0.40 & 1000 & 14 \\
\hline Mo & No Limit & 1000 & $<0.5$ \\
\hline $\mathrm{Cd}$ & 0.50 & $<3$ & $<0.5$ \\
\hline Sn & 0.10 & 1000 & $<1$ \\
\hline Cs & No Limit & - & - \\
\hline $\mathrm{Ba}$ & No Limit & - & - \\
\hline $\mathrm{La}$ & No Limit & $<10$ & $<1$ \\
\hline $\mathrm{Hf}$ & No Limit & 2000 & $<0.5$ \\
\hline $\mathrm{Ta}$ & 0.10 & 5000 & 80 \\
\hline $\mathrm{W}$ & 0.10 & 65 & $<2.5$ \\
\hline $\mathrm{Re}$ & No Limit & - & - \\
\hline $\mathrm{Pb}$ & 0.10 & 1000 & $<0.5$ \\
\hline $\mathrm{Bi}$ & 0.10 & 50 & $<0.5$ \\
\hline Th & 1.0 & 1300 & 10 \\
\hline $\mathrm{U}$ & 0.10 & 656 & 20 \\
\hline $\mathrm{Am}$ & No Limit & 1000 & 130 \\
\hline $\mathrm{C}$ & No Limit & 1800 & 15 \\
\hline $\mathrm{Tm}$ & 0.20 & 1350 & $>10$ \\
\hline $\mathrm{Ir}$ & 0.50 & 4500 & 110 \\
\hline
\end{tabular}




\section{Zone Refining Method of Purification}

The term zone refining denotes a method of controlling the distribution of soluble impurities in crystalline materials ${ }^{4}$. In this method, a short molten zone travels slowly through a relatively long crystalline rod, and as the zone travels it redistributes these impurities in the rod (Figure 2). Depending on the equilibrium distribution coefficient $k$ (i.e., the ratio of the slopes of the solidus and liquidus lines of the solvent-impurity binary phase diagram), the solid-liquid interface that freezes as the molten zone passes acts to either reject or attract impurities (Figure 3). Typically, a series of molten zone passes are induced through the rod in one direction, thereby concentrating impurities at one end or the other and purifying the remainder of the rod. After refinement operations are completed, the portion of the rod containing the high concentration of impurities is removed leaving the rod with an overall lower concentration of impurities. The ultimate efficiency of zone refining and an optimized determination of the portion of the rod to be removed are discussed below.

\section{Induction Coil}

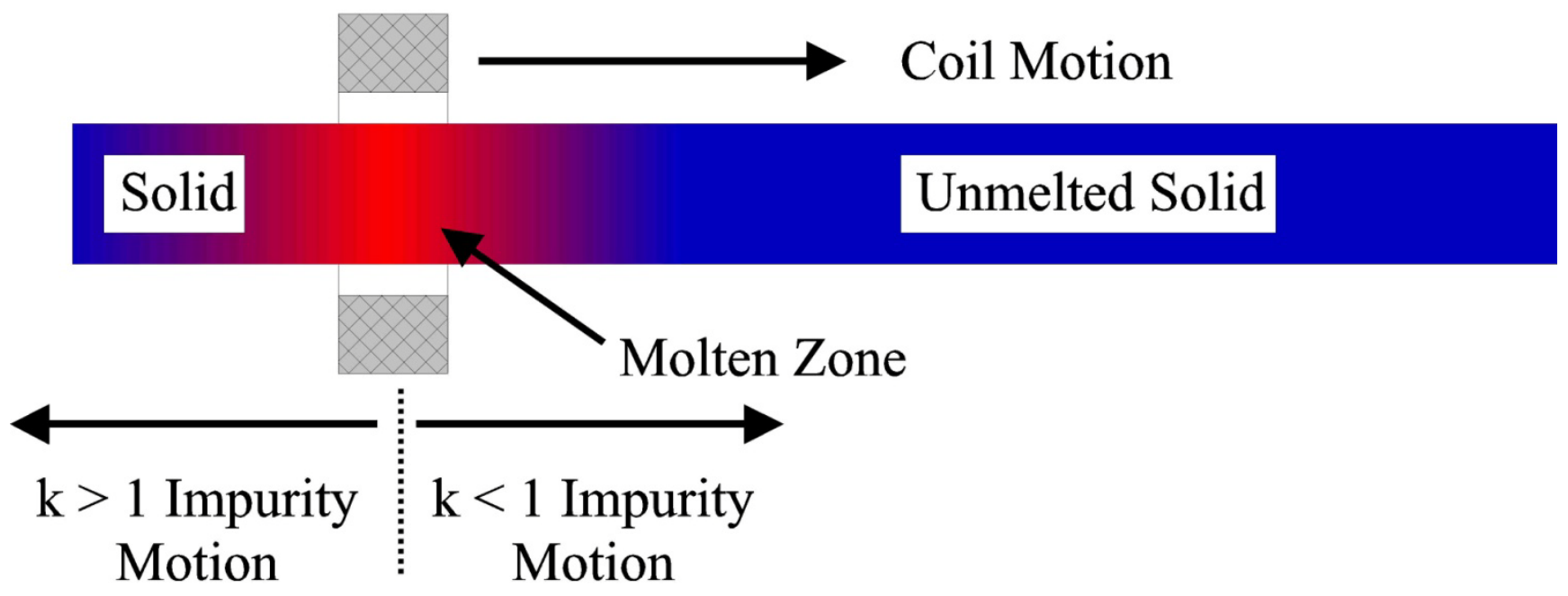

Figure 2 Schematic representation of zone refining of a metal rod by induction heating.

Effective zone refining is a batch technique, in that successive operations are performed on a single batch of material. As such, it has certain limitations; the most serious being the decrease in efficiency of zone passes as their number increases. After many zone passes, the impurity distribution approaches a steady state or ultimate distribution that represents the maximum attainable segregation. When this state 


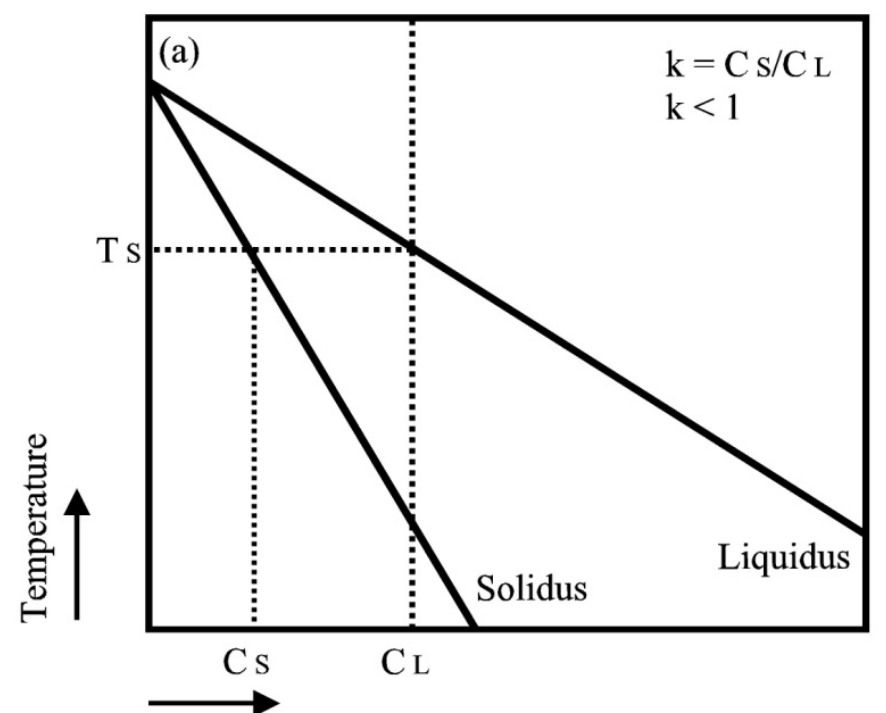

Impurity Concentration

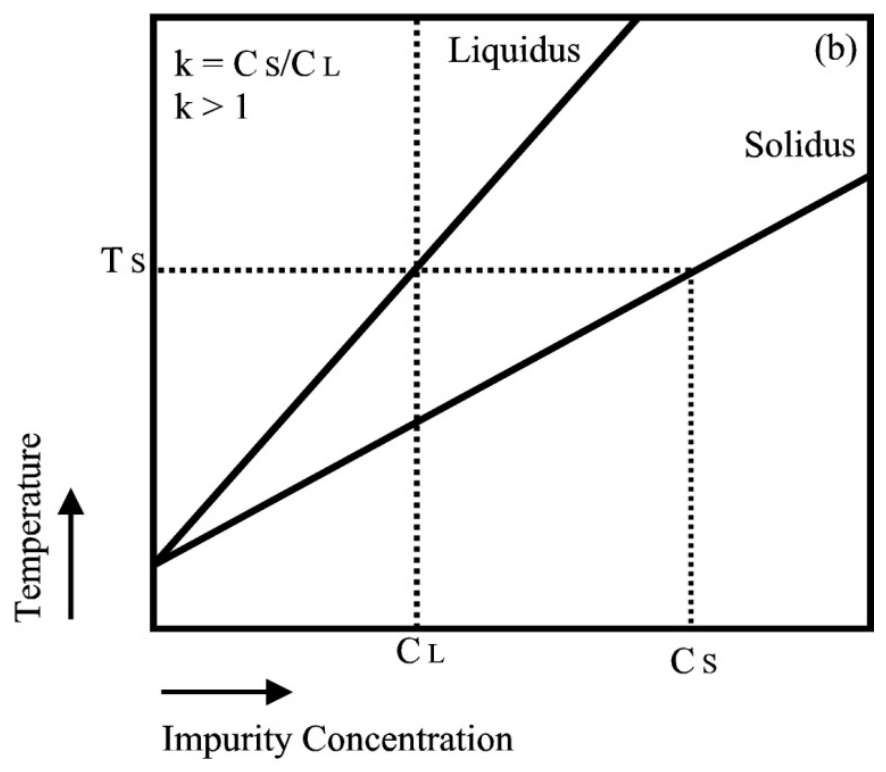

Impurity Concentration

Figure 3 Regions of solvent-impurity binary phase diagrams in which the freezing temperature of the solvent is lowered (a) and raised (b) by the addition of the impurity. Equilibrium distribution coefficients $k$ 's are defined for each situation, where $C_{S}$ and $C_{L}$ are the impurity concentration in the solid and liquid phases, respectively.

is reached, the forward moving flux of impurities due to the freezing action of the zone is, at all points in the rod, opposed by an equal backward flux due to the mixing action of the zone. The equation for the ultimate distribution (i.e., concentration per unit length) has been derived in Ref. 4 to be,

$$
C(x)=A e^{B x}
$$

where $A$ and $\mathrm{B}$ are constants determined according to the following equations:

$$
\begin{aligned}
& k=\frac{B l}{e^{B l}-1} \\
& A=\frac{C_{o} B L}{e^{B L}-1}
\end{aligned}
$$

Here, $C_{o}$ denotes the initial average impurity concentration in units of impurity per unit volume, $l$ denotes the molten zone length and $L$ denotes the ingot length. The ultimate distributions for various values of equilibrium distribution coefficients $(k)$ and a normalized initial liquidus concentration $\left(\mathrm{C}_{\mathrm{L}}=1\right)$ are shown in Figure 4.

From the plots in Figure 4, a determination can be made of the optimized portion, of a zone-refined rod, to remove so as to reduce the overall threshold concentration of a target impurity having a particular $k$ 
value. In order to determine the overall residual concentration in a rod processed in such a manner, the ultimate distribution can be integrated and normalize as follows,

$$
\frac{\int_{L_{I}}^{L_{F}} A e^{B x} d x}{\int_{L_{I}}^{L_{F}} d x}=\frac{A}{B}\left(\frac{e^{B L_{F}}-e^{B L_{I}}}{L_{F}-L_{I}}\right)
$$

where $L_{I}$ and $L_{F}$ are the initial and final rod ends with respect to the original rod length. Given this method of optimization, plots of overall residual concentration are plotted in Figure 5 for various values of $k$ and various portions (percentages) of the zone-refined rod ends removed.

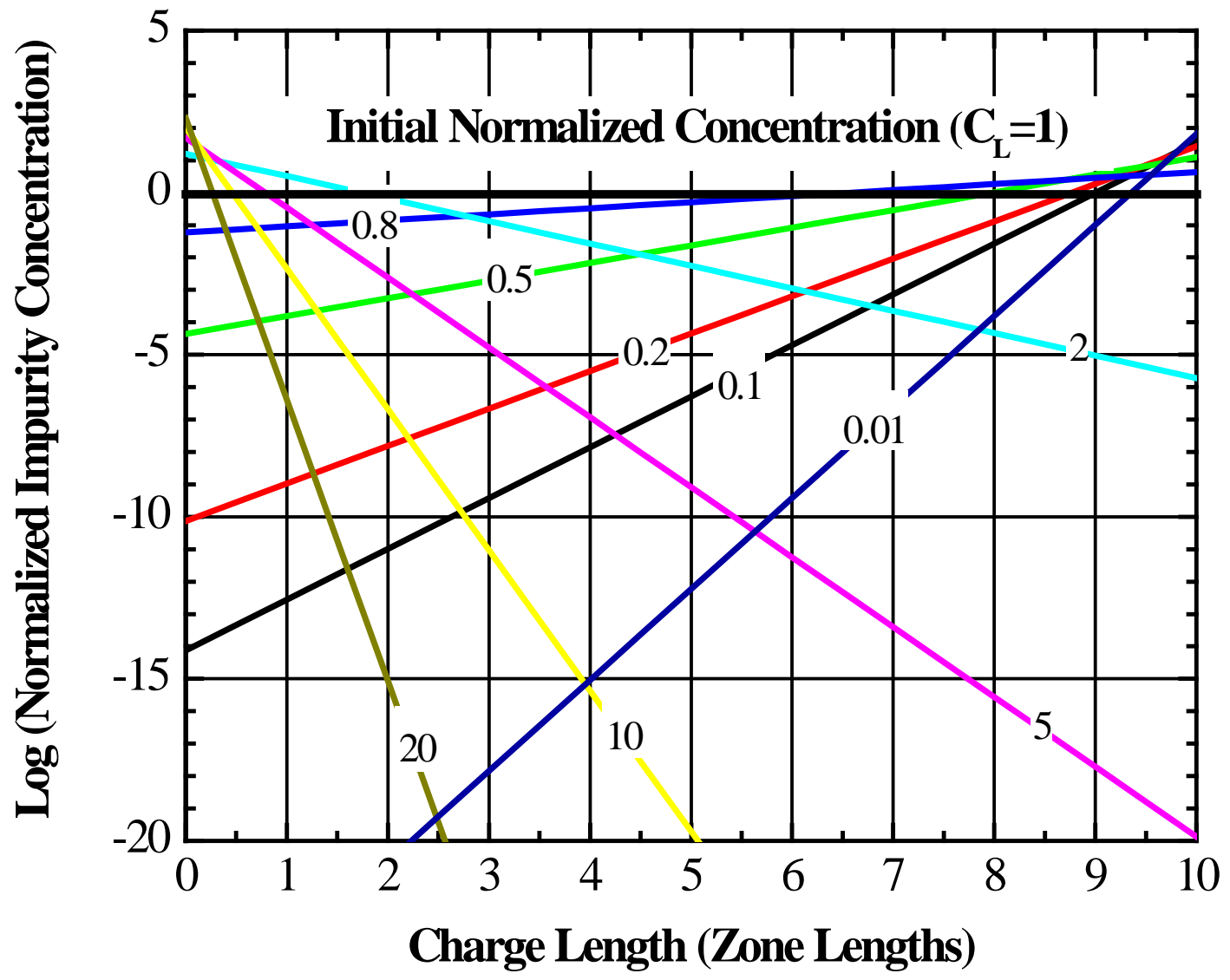

Figure 4 Ultimate distributions for various values of equilibrium distribution coefficients $(k)$ and a normalized initial liquidus concentration $\left(\mathrm{C}_{\mathrm{L}}=1\right)$.

Zone-refining of Pu has been performed here at LANL and other laboratories. ${ }^{5,6}$ Blau utilized zone refining to reduced the total impurity content of double electro-refined Pu from 600ppm (99.94\%) to 
174ppm (99.98\%) of which 110ppm was $\mathrm{U}^{6}$ In that same study, nineteen elements, including Fe and $\mathrm{Ni}$, were reduced to quantities below minimum detectable limits.

Based on the research described in References 5 and 6 and Pu alloy binary phase diagram ${ }^{7}$ estimates, Table 2 was generated as a guide to aid in the optimization of Pu purification via zone refining. From Table 2 and Figure 5, it is expected that the most difficult impurities to remove by zone refining will be those with $k$ values of $0.4<k<1.8$, such as, $\mathrm{Al}, \mathrm{Ti}, \mathrm{Cu}, \mathrm{Ga}$ and $\mathrm{Zr}$. Removal of these impurities to sufficiently low levels may require multiple cycles of zone refining and rod end removal. Also, collection of high impurity concentration rod ends for periodic ER runs seems a proper solution to the issue of high impurity concentration build up in the material stockpile.

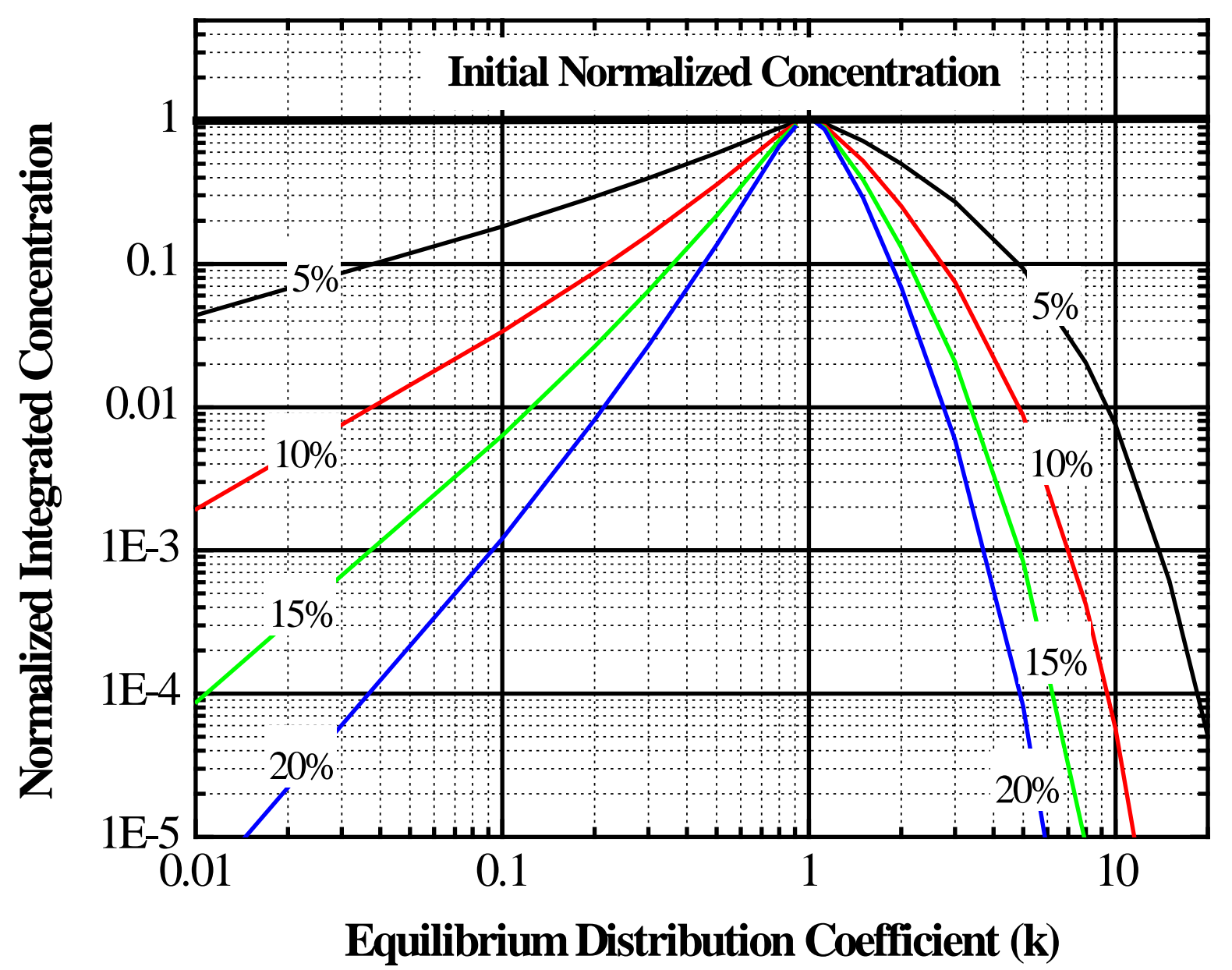

Figure 5 Normalized integrated concentrations for various equilibrium distribution coefficient values and percentages of zone-refined rod ends removed. 
Table 2 Equilibrium distribution coefficients of impurities in $\mathrm{Pu}$ for those impurities listed in specifications for DOR product/ER feed (Table 1) and listed concentrations.

\begin{tabular}{|c|c|c|}
\hline \multirow{2}{*}{$\begin{array}{l}\text { Elemental } \\
\text { Impurity }\end{array}$} & \multicolumn{2}{|c|}{ Distribution Coefficients of Impurities in Plutonium } \\
\hline & Binary Phase Diagram Estimates ${ }^{7}$ & Other Sources ${ }^{5,6}$ \\
\hline $\mathrm{Li}$ & $\infty$ (Immiscible) & \\
\hline $\mathrm{Be}$ & 0.13 & \\
\hline B & 7000 & \\
\hline $\mathrm{Na}$ & $\infty$ (Immiscible) & \\
\hline $\mathrm{Mg}$ & 1870 & \\
\hline $\mathrm{Al}$ & 1.6 & 3.6-6.0 \\
\hline $\mathrm{Si}$ & 0.38 & \\
\hline $\mathrm{K}$ & $\infty$ (Immiscible) & \\
\hline $\mathrm{Ca}$ & $\infty$ (Immiscible) & \\
\hline Sc & 4 & \\
\hline $\mathrm{Ti}$ & 1.8 & \\
\hline $\mathrm{V}$ & 0.18 & \\
\hline $\mathrm{Cr}$ & 0 & 0.3-0.77, 0.6 \\
\hline $\mathrm{Mn}$ & 0 & \\
\hline $\mathrm{Fe}$ & 0.3 & $0.46-0.96,0.6$ \\
\hline Co & 0.22 & $0.28-0.67,0.8$ \\
\hline $\mathrm{Ni}$ & 0.25 & $0.26-0.65,0.7$ \\
\hline $\mathrm{Cu}$ & 0.4 & 0.39-0.92 \\
\hline $\mathrm{Zn}$ & 9 & \\
\hline $\mathrm{Ga}$ & 1.6 & $3.5-4.0$ \\
\hline $\mathrm{Rb}$ & ? (No Phase Diagram) & \\
\hline $\mathrm{Sr}$ & $\infty$ (Immiscible) & \\
\hline $\mathrm{Y}$ & 29 & \\
\hline $\mathrm{Zr}$ & 1.8 & \\
\hline Mo & 1000 & \\
\hline Cd & $\infty$ (Immiscible) & \\
\hline Sn & 0 & \\
\hline Cs & ? (No Phase Diagram) & \\
\hline $\mathrm{Ba}$ & $\infty$ (Immiscible) & \\
\hline $\mathrm{La}$ & $\infty$ (Immiscible) & \\
\hline
\end{tabular}




\begin{tabular}{|c|c|c|}
\hline \multirow{2}{*}{$\begin{array}{l}\text { Elemental } \\
\text { Impurity }\end{array}$} & \multicolumn{2}{|c|}{ Distribution Coefficients of Impurities in Plutonium } \\
\hline & Binary Phase Diagram Estimates ${ }^{7}$ & Other Sources ${ }^{5,6}$ \\
\hline Hf & 2.9 & \\
\hline Та & 192 & \\
\hline $\mathrm{W}$ & 1540 & \\
\hline Re & $>75$ & \\
\hline $\mathrm{Pb}$ & 220 & \\
\hline $\mathrm{Bi}$ & 6000 & \\
\hline Th & 0.14 & \\
\hline $\mathrm{U}$ & 0 & 0.15 \\
\hline Am & 5 & 10.4 \\
\hline $\mathrm{C}$ & 22 & \\
\hline $\mathrm{Tm}$ & 540 & \\
\hline Ir & ? (No Phase Diagram) & \\
\hline
\end{tabular}

\section{Benefits of Zone Refining Actinides}

Reestablishment of plutonium zone refining and levitation distillation capabilities at LANL would provide an invaluable addition to overall programmatic and fundamental plutonium materials science and metallurgy efforts. In particular, this capability would benefit the programmatic efforts in the following ways:

- to refine aged $\mathrm{Pu}$ of decay daughter products such as $\mathrm{U}, \mathrm{Am}, \mathrm{Np}$ and He thus reducing the impurity burden on the Pu feedstream;

- to serve as an isolated facility capable of purifying other $\mathrm{Pu}$ isotopic blends (i.e., ${ }^{242} \mathrm{Pu},{ }^{238} \mathrm{Pu}$, accelerated aging $\mathrm{Pu}$, etc.) and other actinides (i.e., Np, U, etc.);

- to provide experimentally relevant data of the thermodynamic and mechanical constitutive properties of high purity Pu and its alloys of interest for the validation of physics based models;

- to assess the impact of new manufacturing process variables (i.e., chemistry, thermo-mechanical treatment, etc.) on Pu alloy materials properties and develop a quantitative understanding of how these process variables determine the microstructure and composition of Pu alloys which ultimately control their critical performance properties; and

- to validate improved materials properties models for the computational predictions of primary performance EOS and spall data from in small scale and integrated experiments. 


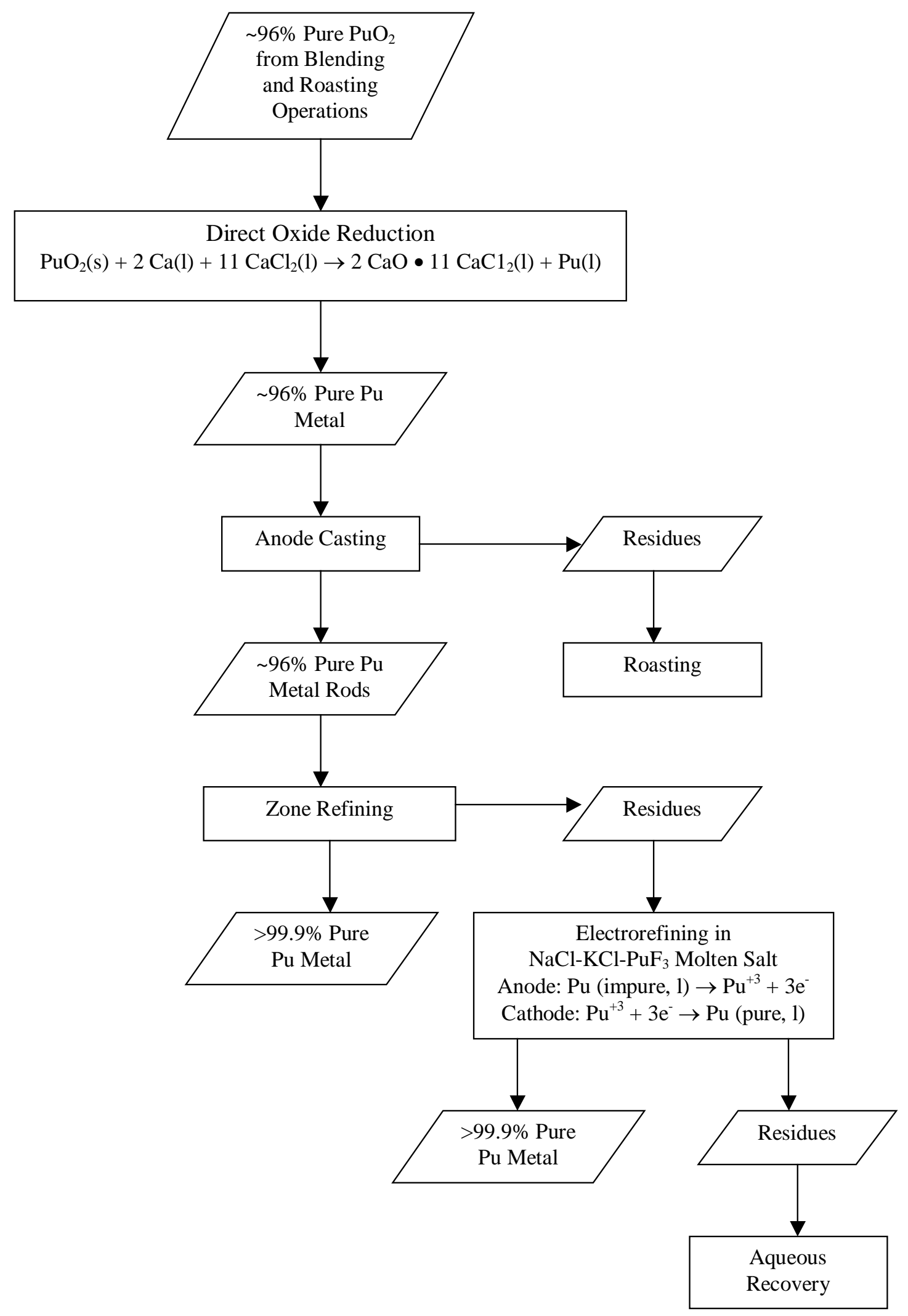

Figure 6 Flow Diagram of the processing steps for the proposed $\mathrm{PuO}_{2}$-to-Pu metal purification operations. 
This materials processing capability would provide source material for single crystal growth and thin film sputtering activities, which are necessary to extend our fundamental understanding of Pu bulk and surface properties. Zone refining and levitation distillation capabilities are vital for a high-quality research-grade crystal growth effort.

Furthermore, “clean” elemental Pu is necessary for numerous programmatic activities having precious little surplus. As such, Figure 6 is a schematic of the proposed processing route for performing $\mathrm{Pu}$ purification in such a manner with periodic runs through the ER process to reduce the ultimate buildup of unwanted impurities from the materials stockpile.

\section{References:}

1) L. J. Mullins and C. L. Foxx, "Direct Reduction of ${ }^{238} \mathrm{Pu}_{2}$ and ${ }^{239} \mathrm{PuO}_{2}$ to Metal", Los Alamos National Laboratory report LA 9073 (1982).

2) L. J. Mullins and A. N. Morgan, "A Review of Operating Experience at the Los Alamos Plutonium Electrorefining Facility, 1963-1967”, Los Alamos National Laboratory report LA 8943 (1981).

3) L. J. Mullins, D. C. Christensen and B. R. Babcock, "Fused Salt Processing of Impure Plutonium Dioxide to High-Purity Plutonium Metal”, Los Alamos National Laboratory report LA-9154-MS (1982).

4) W. G. Pfann, “Zone Melting”, Second Ed., John Wiley \& Sons, Inc., New York, 1966.

5) R. E. Tate and R. W. Anderson, "Some Experiments in Zone Refining Plutonium”, in Extractive and Physical Metallurgy of Plutonium and its Alloys, W. D. Wilkinson, ed., Interscience Publishers (1959) and Los Alamos National Laboratory report LADC-3700 (1958).

6) M. S. Blau, “Zone refining of Plutonium Metal”, Journal of Radiation and Nuclear Chemistry, 235, 41-45 (1998) and Los Alamos National Laboratory report LAUR-94-2627 (1994) and references therein.

7) M. E. Kasser and D. E. Peterson, ed., "Phase Diagrams of Binary Actinide Alloys”, ASM International (1995). 